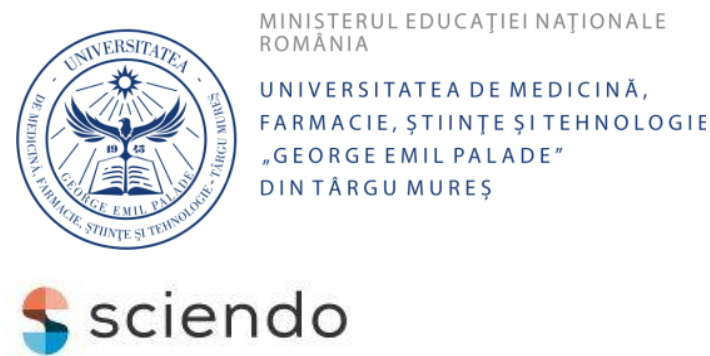

\author{
Acta Marisiensis. Seria Technologica \\ Vol. 16 (XXXIII) no. 2, 2019 \\ ISSN 2668-4217, ISSN-L 2668-4217
}

10.2478/amset-2019-0012

\title{
THE PUZZLE GAME BETWEEN DESIGN, SCIENCE AND SKILLS
}

\author{
Bogdan BUCUR \\ George Emil Palade University of Medicine, Pharmacy, Science, and Technology of Targu Mures \\ 38 Gheorghe Marinescu st., no. 38, 540139, Targu Mures, Romania \\ bogdan.bucur@umfst.ro
}

\begin{abstract}
The present paper presents an alternative method regarding the practical solution of defining the puzzle game in terms of design, graphics, 3D modeling and manufacture of the puzzle game. The practical example of making a puzzle game defined by assembling components resulting the administrative map of Romania.
\end{abstract}

Keywords: AutoCAD, Inventor, 3D model, 3D Printing, CorelDraw, puzzele game, design, graphics

\section{Introduction}

The puzzle toys presents an activity suitable for children, a clever game that gives the little ones the first lessons on patience and concentration. Most games play a very important role in our lives, especially those that require us to think. The benefits of the puzzles we can discover from the first years of life, they train our mind, facilitate our problem solving and develop different skills of concentration, science and skill.

The puzzle toys are the most important part of the learning process for the little ones, [6],[7],[8],[9].

With the digital age, it is becoming more attractive for children and parents alike, presenting an alternative to using gadgets, applications or other technological devices. The phone or tablet are easyto-use tools for parents because they can keep the child busy for longer. But there is a very large minus, from a tactical point of view they do not offer the same experience.

The puzzle toys are complex activities for both adults and children in particular [14]. This type of toy's game involves patience, concentration, curiosity but also reflection [1],[2],[3]. By applying the puzzle game, a number of advantages are pursued, respectively: it improves hand-eye coordination, concentration and skill, but there are many more benefits: it teaches us to be persistent. Solving puzzles are challenges of the mind that will help you build this quality. The puzzle is a child-friendly activity, a clever game that offers little ones and not only the first lessons on patience and concentration.

The puzzle involves combining one piece with another piece following the final assembly of an original image. To make a puzzle toys it is necessary a manual ability, attention, a good orientation in space and respectively, spirit of observation, [18]. Existing offer in the terms of the puzzle toys is very diverse. In this paper presents an educational of the puzzle toys model regarding the assembly of the on the administrative map of Romania country, identifying one by one combining parts in terms of geography and neighbors.

In Fig. 1 you can see the structure of the working method approached in establishing the theoretical working stages for defining the puzzle toys. Thus the purpose of the puzzle toys is to know and identify all the administrative areas of Romania, as well as the geographical structure of each parts of county and through the game you can developed the perseverance, creativity and curiosity.

Acceptance of the challenges is the first step in developing perseverance. Solving puzzles is challenging the mind that will help to build and acquire this quality [3].

(C) 2019 Published by University Press. This is an open access article licensed under the Creative Commons Attribution-NonCommercial-NoDerivs License (http://creativecommons.org/licenses/by-nc-nd/3.0/). 


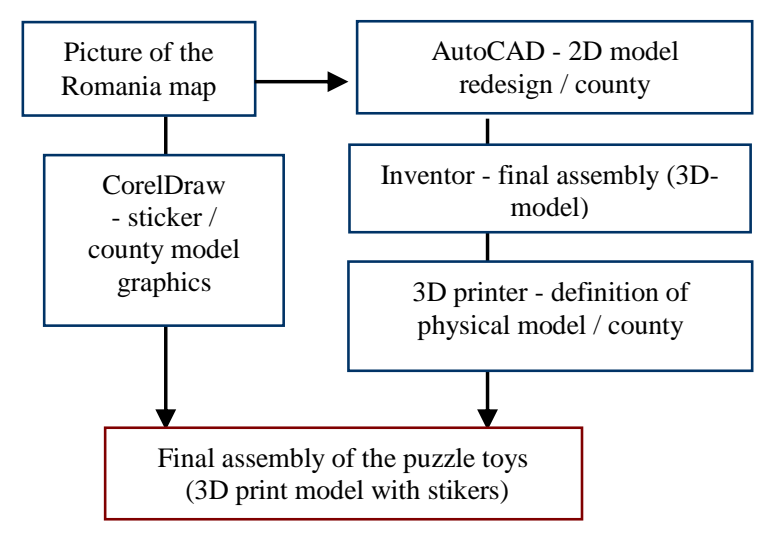

Fig. 1: Working method

\section{Working method}

Working method presents the following steps in a sequential order, as is defined in the diagram of Fig.1.

\section{Step 1. Sketch drawing}

Based on images taken from [17], which define the map of Romania, respectively the geographical and administrative map. For the beginning, a sketch is established on paper support to establish a relation between proportion and size, applied on a standardized format, [12], [15].

This format will be respected in all work environments in which the components of a. 1e are defined. The set format is A2, so you c identify the details of the cartons during the as a puzzle toys.
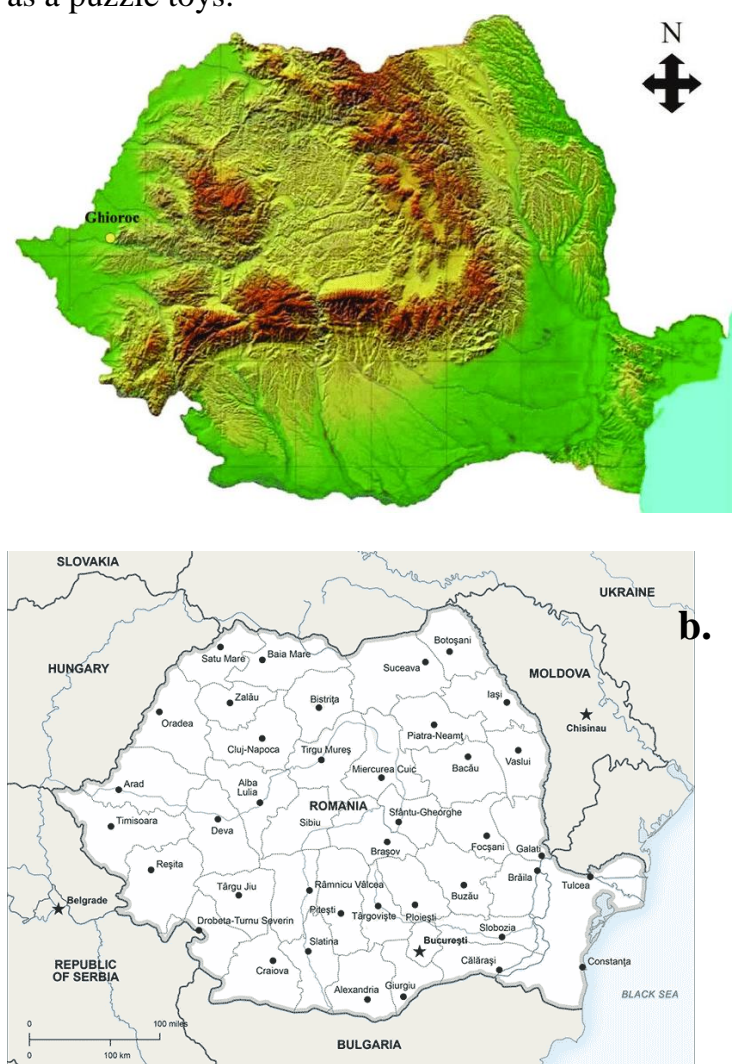

Fig. 2: Map of Romania: a.the relief structure, b.the administrative structure of the counties [17]

\section{Step 2. Autodesk-AutoCAD environment}

The picture is imported in AutoCAD environment and bring to scale in A2 format, a corresponding on appropriate layer, and the next step having to be redesigning a closed outline of the specific geometry for each administrative section, defined all over the country using the Pline command [4], [16].

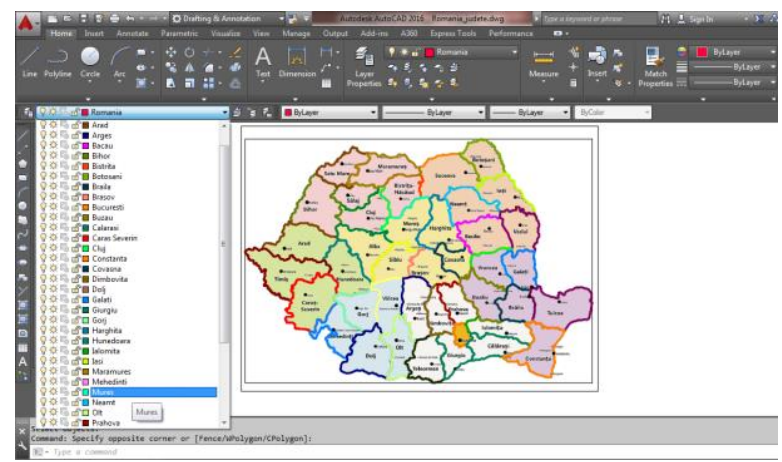

Fig. 3: Model 2D-AutoCAD: redesigning the administrative map of Romania

\section{Step 3. Mediul Autodesk-Inventor}

In order to obtain the 3D virtual model, necessary after the physical model is created, a 3D object will be created for each cardboard, using the Inventor working environment, [11]. Each administrative structure is imported from the AtoCAD environment according to the configuration established in step 2 . Using the extruded command, the thickness of the carton is defined, respectively of $3 \mathrm{~mm}$.

In the Inventor environment you can imports one by one the contour from the AutoCAD environment that defines the administrative area of each county, resulting the $3 \mathrm{D}$ model.

The assembly of the 3D modeled objects will be done in the Assembly module in the AutodeskInventor environment by using the specific constraints [11].

In other news, using the 3D model assembled in Inventor allows the creation of a database for defining a virtual pazzle game that can be accessed from assisted platforms, respectively: tablet, mobile phone or electronic game, [5],[10 ],[13].

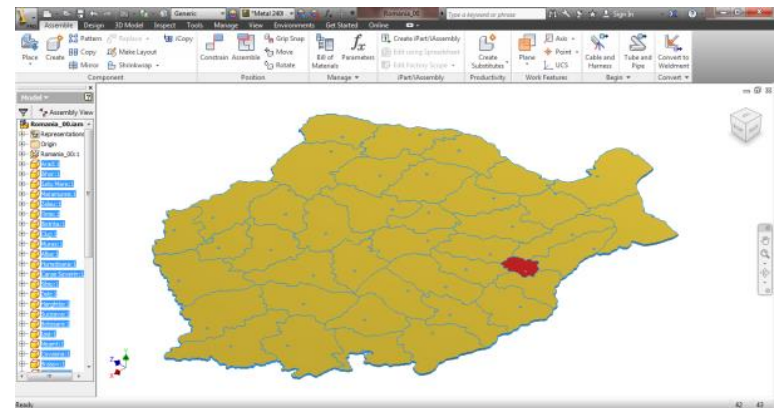

Fig. 4: Inventor 3D model: 3D structure model assembly of the administrative Romania map 


\section{Step 4. Design of the 3D Printing Process}

For each 3D model defined in the Inventor, a physical model will be made from PLA-type thermoplastic material using the 3D printer manufacture.

For this stage of work, the 3D model is exported from the Inventor environment with STL extension and the $3 \mathrm{D}$ printing technological parameters transposed into the attached G-code in the source code are defined to each 3D model object.

In Fig. 5 you can see the 3D model for an object that is exported in the $3 \mathrm{D}$ printing program, and also in Fig.6 you can see the interface of the program specific to the $3 \mathrm{D}$ printer.

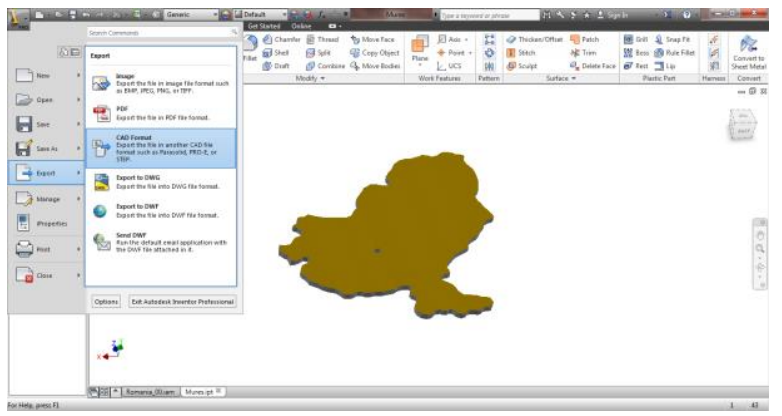

Fig. 5: The detail of 3D model-Inventor

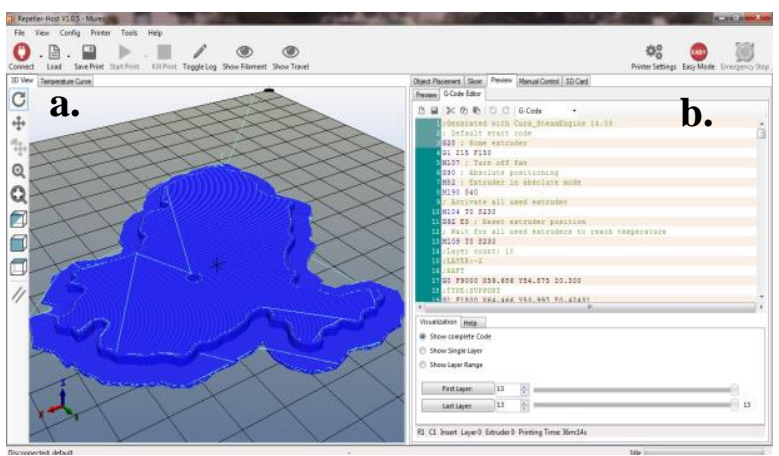

Fig. 6: a.Model for 3D printing, b.G-code: Printing parametes

The 3D Printing comply with the scaling factor of the 3D model (Inventor AutoCAD) and the attached G-code program are defined by $3 \mathrm{D}$ printer with printing parameters defining to manufacture of the physical model, according to Table 1 .

Tabel 1: Printing parametes

\begin{tabular}{|l|l|}
\hline Extruder Temperature & $230{ }^{0} \mathrm{C}$ \\
\hline Print Speed & $60 \mathrm{~mm} / \mathrm{s}$ \\
\hline Infil Density & $95 \%$ \\
\hline Estimated Printing Time & $36 \mathrm{~m}: 14 \mathrm{~s}$ \\
\hline Layer Count & 13 \\
\hline Filament needed & $3616 \mathrm{~mm}$ \\
\hline
\end{tabular}

The manufacturing process and the printed product it can be seen in fig 7 .

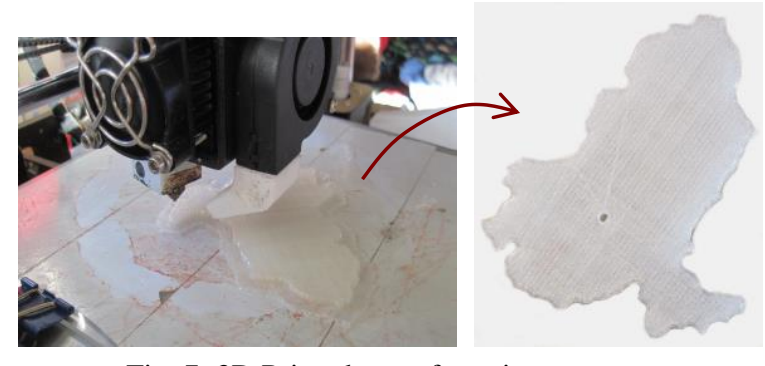

Fig. 7: 3D Printed manufacturing proccess

Step 5. CorelDraw environment

For definatin of the relief of Romanian map it will be used the CorelDraw environment in order to define the graphical relief of the Romanian map, in which the geographical of Romania map will be imported which presents the differentiated relief structure on specific colors: plains, hills and mountains. Over this image we can import from AutoCAD, the administrative map of Romania with 42 counties and the capital Bucharest, just redesigned in stage 2 .

Using techniques of graphic modeling and image cropping, the surfaces attached to each administrative location will be defined resulting to make a good printing stiker.

In the CorelDraw environment, the specific graphics of the relief are made for each part of administrative structure, and then the graphics attached to each carton are printed on self-adhesive media, respecting the scaling factor and the original image format imported from the AutoCAD environment.

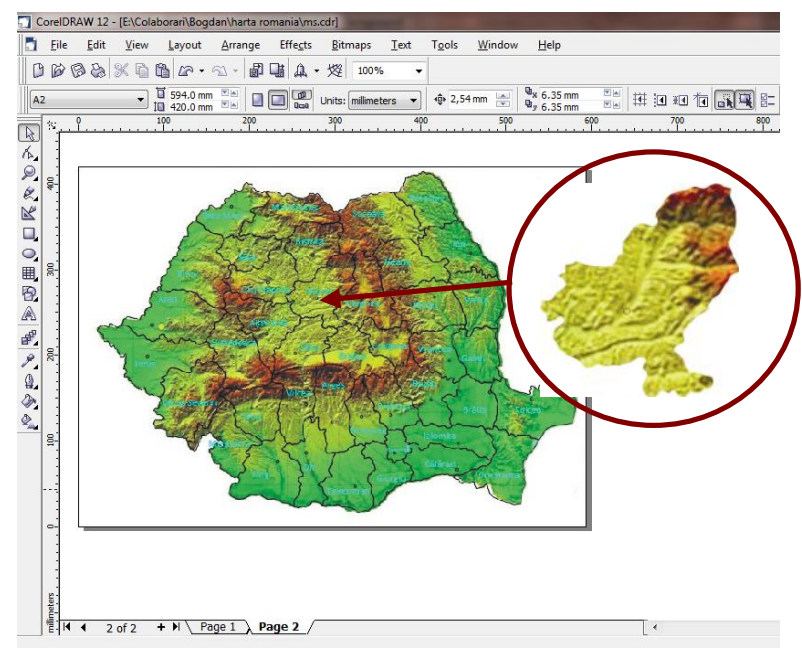

Fig. 8: Stiker / county pattern graphics - CorelDraw environment 

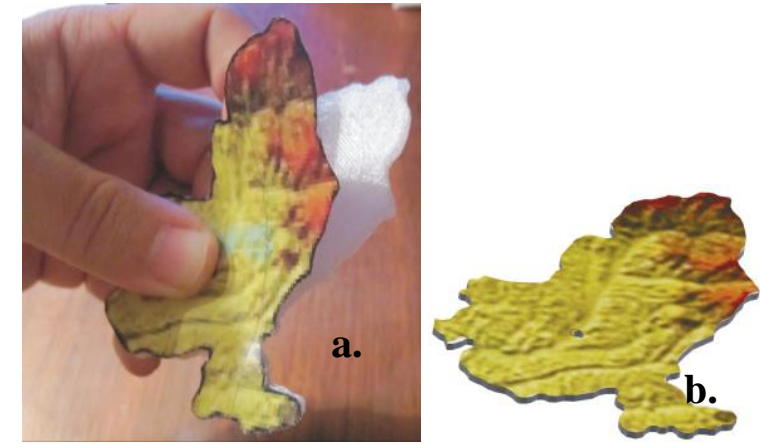

Fig. 9: a.Stiker model, b.Puzzles carton (final result)

\section{Step 6. Final result}

Assemble the whole picture with all 3D printed objects by combining the 43 locations resulting the administrative map of Romania as a puzzle toys on standard format A2.

\section{Results and discussion}

Following step-by-step the process for defining and creating the structure of the pazzle toys, it results by the final assembly of the all parts the geographical and administrative of Romania map like a puzzle toys game. In Fig.10 you can see a detail of the puzzle toy.

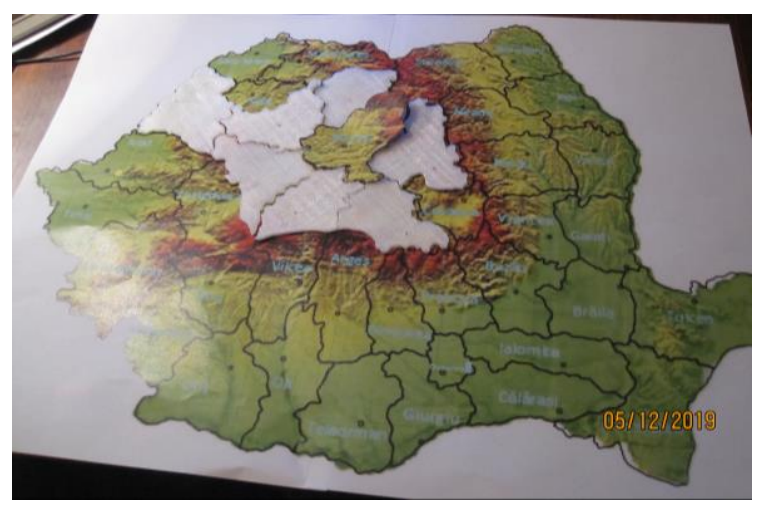

Fig. 10: Detail puzzle: the geographical and administrative map's of the Romania

\section{Conclusions}

The paper presents a practical exercise of design, graphic editing and manufacturing (3D printing) finally offering the finished product and the puzzle game made from cardboard assembled and defined by PLA. One of the advantages of the puzzle game is a clear result, since the card assembly reconstitutes the original image.

Thus, at the thought of succeeding and seeing the result of the work, it offers an added confidence in their own forces, while also opening up the approach of increasingly difficult tasks.

The 3D model assembled in the AutodeskInventor environment can be a database for the creation of interactive elements such as educational or media support.

The 3D model assembled in Inventor it can be allows the creation and definition of a dynamic virtual puzzle toys game that runs on assisted platforms, respectively: tablet, mobile phone or other digital applications, in Fig.11 you can see the final result.

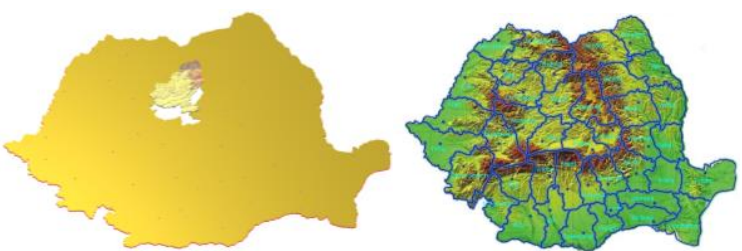

Fig. 11: Final result: the geographical and aministrativ map of Romania country (virtual puzzles stikers)

The game assembly of the puzzle cards ensures through synoptic learning, the discovery of the relief forms as well as the geographical identification of the administration at the county level in the territory of Romania.

\section{References}

[1] Amory, A. (2001), Building an Educational Adventure Game: Theory, Design, and Lessons, Journal of Interactive Learning Research, vol. 12, no. 2, ISSN 1093023X, Publisher: Association for the Advancement of Computing in Education (AACE), Waynesville, NC.

[2] Amory A., Seagram R. (2003), Educational game models: conceptualization and evaluation: the practice of higher education, South African Journal of Higher Education, vol. 17, Issue 2, pp. 206-217.

[3] Bourrassa B., Serre F., Ross D. (2003), Apprendre de son expérience, Presses de l'Université du Québec.

[4] Bucur, B. (2013), Infographics. Flat design in the AutoCAD environment (Infografică. Proiectarea plană în mediul AutoCAD), "Petru Maior" Publishing House, Tîrgu-Mureș.

[5] Kiili K. (2005), Digital game-based learning: Towards an experiential gaming model, The Internet and Higher Education, vol. 8, Issue 1, 1st Quarter 2005, Tampere University of Technology, Finland, pp.13-24.

[6] Meuwly M., Heiniger J. (2007), Games with purpose psychosocial, Terre des hommesLausanne.

[7] Mercy C. (2004), Teaching life skills through games, Bam, Iran.

[8] Manuel d'Education Physique à l'école - jeux, Lausanne, Suisse, 1997.

[9] Nicola I. (1992), Pedagogy, Didactic and Pedagogical Publishing House, Bucureşti.

[10] Neal L. (1990), Implications of computer games for system design, Proceeding: INTERACT '90 Proceedings of the IFIP TC13 Third Interational Conference on Human-Computer Interaction, ISBN 0-444-88817-9, North-Holland Publishing Co. Amsterdam, The Netherlands, pp.93-99. 
[11] Pozdirca A., Kalman A., Chetan P. (2004), Inventor-Parametric modeling (Inventor-Modelare parametrica), "Petru Maior" Publishing House, Tîrgu-Mureș.

[12] Tero, M., Bucur, B., Bratu, Gh. (2013), Descriptive Geometry and Technical Drawing, NapocaStar Publishing House, Cluj-Napoca.
[13] Quinn C. (1994), Designing educational computer games, Proceedings of the IFIP TC3/WG3.2 Working Conference on the Seign, Implementation and Evaluation of Interactive Multimedia in University Settings: Designing for Change in Teaching and Learning, ISBN 0-44482077-9, Elsevier Science Inc. New York, NY, USA, pp. $45-57$. 